\title{
Spectrum of musculoskeletal disorders in Nigerians with types 2 diabetes mellitus: prevalence and predictors
}

\author{
H. Olaosebikan', A. Azenabor², R. Akintayo ${ }^{3}$, O. Adelowo', \\ A. Ogbera ${ }^{4}$, A. Brodie-Mends ${ }^{5}$ \\ ${ }^{1}$ Rheumatology Unit, Department of Medicine, Lagos State University College of Medicine/Lagos \\ State University Teaching Hospital, Lagos Nigeria; ${ }^{2}$ Clinical chemistry Unit, Department of Medical Laboratory \\ Science, College of Medicine, University of Lagos, Lagos, Nigeria; ${ }^{3}$ Rheumatology Unit, \\ Department of Medicine, University of Ilorin Teaching Hospital, Ilorin, Nigeria; ${ }^{4}$ Endocinology unit, \\ Department of Medicine, Lagos State University College of Medicine/Lagos State University Teaching \\ Hospital, Lagos Nigeria; ${ }^{5}$ Medical Laboratory Technology Unit, Department of Medicine, \\ Lagos State University College of Medicine/Lagos State University Teaching Hospital, Lagos Nigeria
}

\section{SUMMARY}

Musculoskeletal (MSK) conditions are more frequently found among patients with diabetes mellitus (DM) than in the non-diabetics. Despite several reports outside Africa, they have been under-studied among Africans. This study aimed to assess the overall prevalence and predictors of MSK conditions in Nigerian with types 2 diabetes mellitus (T2DM). A total of 268 adult with T2DM and 268 non-diabetic controls were recruited. All study subjects had their socio-demographics and clinical parameters obtained using interviewer-administered questionnaire. Musculoskeletal conditions among study subjects were classified using validated criteria and case definitions. Musculoskeletal disorders (MSKD) were significantly more frequent amongst subjects with DM (56\% vs $22 \%, \mathrm{OR}=4.5 \mathrm{p}=0.001)$. Osteoarthritis $(9.3 \%$ vs $4.1 \%, \mathrm{p}=0.016)$, lumbosacral spondylosis (5.6\% vs $2.2 \%$, $\mathrm{p}=0.045)$, limited joint mobility ( $13.8 \%$ vs $5.6 \%, \mathrm{p}-0.001)$, adhesive capsulitis ( $4.5 \%$ vs $1.5 \%$, $\mathrm{p}-0.042)$ and rotator cuff tendinitis $(3.7 \%$ vs $0.4 \%, \mathrm{p}=0.006)$ were more frequent in DM subjects than in controls. Logistic regression showed that age $(\mathrm{OR}=2.1, \mathrm{CI}=1.5-2.6)$ and waist circumference $(\mathrm{OR}=3.0, \mathrm{CI}=2.6$ 3.4) are independent predictors of MSKD among patients with diabetes. This study found higher prevalence of MSKD among diabetic subjects. It also identified certain factors associated with MSKD among patients with diabetes mellitus.

Key words: Spectrum, musculoskeletal disorders, nigerians, types 2 diabetes.

Reumatismo, 2019; 71 (4): 209-217

\section{INTRODUCTION}

Musculoskeletal disorders (MSKD) in diabetes mellitus (DM) are common and have been shown to be more prevalent than in persons who do not have DM (1-4). They are under-researched and under-reported compared with well-known micro- and macro-vascular disease in DM. The prevalence of DM in the world, particularly in developing countries, has been on an upward trend. The estimated number of adults with DM in Nigeria in year 2010 was 2.8 million with a prevalence of $3.9 \%$ while the projection for 2030 is 5.3 million with a prevalence of $4.3 \%$ (5). DM is a multisystem disease and the musculoskeletal system is often affected perhaps due to reduced physical activity, obesity and aging. A wide spectrum of MSKD have been described in diabetic patients, and these include limited joint mobility (LJM), carpal tunnel syndrome, DeQuervain's tendinitis, bicipital tendinitis, adhesive capsulitis, finger flexor tenosynovitis (trigger finger), diffuse idiopathic skeletal hyperostosis (DISH), gout, osteoarthritis and several others (6). Some of these conditions arise directly as a consequence of chronic complications of DM, while others have increased incidence in DM due to epidemiologic associations (7). The exact cause of MSK conditions in DM
Corresponding author: Hakeem Olaosebikan, Rheumatology Unit, Department of Medicine, Lagos State University College of Medicine/Lagos State University Teaching Hospital, 1-5, Oba Akinjobi Way, GRA, Ikeja, Lagos Nigeria. PMB: 21266 E-mail: hakeemolaosebikan37@gmail.com 
is not known; however, it was suggested that the metabolic disturbances in DM such as glycosylation of proteins, microangiopathy, neuropathy as well as collagen deposition in skin and periarticular structures, may result in changes observed in the connective tissue structures (8). MSKD may occur in DM of short and long term durations, in any type of DM and may even be the presenting features of the disease (9). Rheumatic hand conditions have been identified as harbingers of undiagnosed DM (10). Similarly, co-existence of MSKD with DM may predict subsequent development of microvascular complications, increase hospital utilisations and worsening quality of life (QOL). Rosenbloom et al. (11) found $83 \%$ risk of microvascular complications after 16 years of DM in the presence of LJM in comparison with a $25 \%$ risk in the absence of LJM. In comparison with persons without DM, diabetic patients had higher 10 year cumulative incidence of MSK pain and hospital visits for MSK pain as well as lower QOL physical component score $(12,13)$. MSKD of DM have been studied elsewhere with varying scope and different prevalence reports. There is only one published case-control study of limited joint mobility (LJM) among DM patients from Nigeria while the other was a case report $(2,14)$.

\section{MATERIALS AND METHODS}

The study was conducted at the endocrine clinic of Lagos State University Teaching Hospital (LASUTH), located in Ikeja, the capital city of Lagos, Nigeria. This study is a cross-sectional comparative study that was carried out over a period of six months. Two hundred and sixty eight adult subjects with type 2 DM (T2DM) were recruited using systematic random sampling technique. Same number of control subjects without DM were recruited from the hospital's member of staff and visiting patient's relatives. Out of 268 control subjects recruited, hospital staff were 154 in number while patient's relatives were one hundred and fourteen.

The Kish's formula $\left(\mathrm{Z}^{2} \mathrm{PQ} / \mathrm{D}^{2}\right)$ for sam- ples size determination in a cross-sectional study was used (15). Sample size was calculated using a tolerable sampling error (D) of 0.05 , confidence interval $(\mathrm{Z})$ of 1.96 and prevalence $(\mathrm{P})$ of $19 \%$ obtained in a Nigeria study on $\mathrm{LJM}^{2}$. The sample size was 262 after allowing $10 \%$ drop out rate. All patients recruited provided informed consent while diabetic patients with traumatic and congenital MSK conditions, those on steroids and those with co-morbid endocrine diseases were excluded from the study. All control subjects were further screened by random blood glucose test. Controls with impaired glucose tolerance, 'DM' range blood glucose and other endocrine diseases were excluded from the study. Approval was granted by the Research Ethics Committee of LASUTH before the commencement of the study and informed and written consent was obtained from the study participants.

\section{(a) Clinical Assessment}

The anthropometrics and blood pressure were assessed in all subjects using standard techniques. Musculoskeletal examination included both the general and specific MSK assessments. General inspection of the subjects for abnormal gait, loss of function, joint deformities, subcutaneous nodules and joint swelling was carried out in all subjects. The joints and peri-articular structures were palpated for swelling, effusions, tenderness, crepitus and warmth while active range of motion of the joints was followed by passive joint mobilizations in subjects with limited active joint motion. Resisted active joint motion, provocative joint manoeuvres and some special tests such as Tinel's and Phalen's test for carpal tunnel syndrome, Finkelstein's test for Dequervain's tendinitis, prayer and table top tests for LJM, were carried out where applicable to identify specific MSK conditions.

\section{(b) Laboratory and radiological assessments}

Fasting and random whole blood glucose were measured for cases and controls, respectively, using a glucometer. In addition, two hour post prandial whole blood glucose 
and HBA1C measurement were carried out for diabetic cases while venous blood sample was collected for determination of ESR, haematocrit, WBC, SUA, HDL cholesterol, triglycerides and hsCRP in all subjects using standard techniques. All subjects were categorized into two groups of presence and absence of anaemia, hyperuricemia, obesity, abdominal obesity, metabolic syndrome, dyslipidaemia, elevated hsCRP, elevated ESR, leucocytosis, hypertension, reduced HDL, and elevated TG. Plain radiographs of the affected joints were done for patients requiring $\mathrm{X}$-rays for definitive diagnosis and to exclude alternative diagnosis.

MSKD among the patients were diagnosed using the validated ACR endorsed criteria (16) for fibromyalgia (FM), gout and osteoarthritis (OA) of the knee, hip and hand. Southampton examination schedule (17) was used for diagnosis of upper limb MSK such as adhesive capsulitis (AC), rotator cuff tendinitis (RCT), bicipital tendinitis (BT), DeQuervain's tendinitis (DQT), carpal tunnel syndrome (CTS), lateral epicondylitis (LE) and medial epicondylitis (ME). Operational definitions were adopted for MSK conditions without classification criteria and for some clinical and laboratory parameters.

\section{Operational definitions for diagnosis of some MSK disorders and metabolic abnormalities}

1) Flexor tenosynovitis (trigger fingers, $T F$ ): Patients having a palpable nodule, usually in the area overlying the MCP joints, and thickening along the affected flexor tendon sheath on the palmar aspect of the finger and hand. The locking phenomenon may be reproduced with either active or passive finger flexion (1).

2) Limited joint mobility (LJM): will be diagnosed by presence of positive 'prayer sign' and 'table top test'.

The "prayer sign," which tests the ability to flatten the hands together as in prayer, facilitating recognition of contractures (11). The "table top test," which assesses the ability to flatten the palm against the surface of a table (11).
3) Plantar fasciitis (PF): heel pain and or plantar heel pain at any time with either plantar heel tenderness or plantar heel pain on passive dorsiflexion of the foot (18).

4) Subacromial bursitis (SB): painful impingement tests on forced passive internal rotation, resisted external rotation and forced passive forward flexion (19).

5) Symptomatic cervical spondylosis $(S C S)$ : Mechanical neck pain or stiffness greater than or equal to 3 months supported by typical radiographic features.

6) Symptomatic lumbar spondylosis (SLS): Mechanical low back pain or stiffness greater than or equal to 3 months supported by typical radiographic features.

\section{Statistical analysis}

Data obtained were analysed using statistical package for social science (SPSS) version 19. All categorical variables were summarized and presented as frequency and percentages while all quantitative variables were expressed as mean and standard deviation (SD), as well as median and inter-quartile range, where applicable while the differences between the categorical variables were compared using Chi-square tests, the difference between the numerical variables were compared using independent $t$ test. The Mann Whitney $U$ test was used to compare non-parametric numerical variables. Binary logistic regression analysis was performed to determine the categorical and numerical predictors of musculoskeletal conditions among the diabetic subjects. Statistical significance was set at $\mathrm{p}$ value $<0.05$.

\section{RESULTS}

\section{Socio-demographic characteristics of the study subjects}

Two hundred and seventy six subjects with T2DM were initially recruited for the study, out of which eight cases had no laboratory results, due to insufficient samples. Also, two hundred and eighty one controls were initially recruited but thirteen were exclude due to impaired glucose tolerance and diabetic range blood glucose. The mean ages of the DM cases and control groups 
were comparable $(59.4 \pm 12.7$ vs $57.3 \pm 12.4$ years, $\mathrm{t}=0.926, \mathrm{p}=0.06$ ). Females constituted more than $70 \%$ of the subjects in both groups. The occupations of the two groups were comparable $(\mathrm{p}=0.281)$ with a significant difference in the level of education between the two groups $(p=0.001)$. Table I shows socio-demographic characteristics of the study subjects.

\section{Prevalence and patterns of musculoskeletal conditions among study subjects}

The prevalence of MSK conditions in diabetic group was higher than in the control group (DM-56\%, control-22\% OR=4.5, $\mathrm{p}=0.0001)$. While some MSK conditions such as OA $(9.3 \%$ vs $4.1 \%$, $\mathrm{p}=0.016)$, symptomatic LS (5.6\% vs $2.2 \%, \mathrm{p}=0.045)$, LJM (13.8\% vs $5.6 \%, \mathrm{p}=0.001)$, AC (4.5 vs 1.5 , $\mathrm{p}=0.042)$ and $\mathrm{RCT}(3.7 \%$ vs $0.4 \%, \mathrm{p}=0.006)$ were significantly more frequent in DM subjects than in the controls, conditions like BT, gouty arthritis, Dupuytren's contracture, and ME were not documented in the controls. The comparisons of the prevalence and types of MSKD between DM and con- trol subjects are shown in Table II.

\section{Factors associated with presence of musculoskeltal conditions among subjects with types $2 \mathrm{DM}$}

Categorical variables

Bivariate analysis using Chi-square statistics showed that female sex $(\mathrm{OR}=2.3$, $\mathrm{p}=0.0007)$, old age $(\mathrm{OR}=2, \mathrm{p}=0.0007)$, long standing $\mathrm{DM}(\mathrm{OR}=12.3, \mathrm{p}=0.001)$, lack of formal education $(\mathrm{OR}=2.1, \mathrm{p}=0.004)$, poor glycaemic control $(\mathrm{OR}=4.8, \mathrm{p}=0.001)$, use of statins $(\mathrm{OR}=9.8, \mathrm{p}=0.001)$, hyperuricemia $(\mathrm{OR}=1.8, \mathrm{p}=0.024)$, hypertension $(\mathrm{OR}=1.8, \mathrm{p}=0.029)$, obesity $(\mathrm{OR}=1.9$, $\mathrm{p}=0.012)$, metabolic syndrome $(\mathrm{OR}=1.8$, $\mathrm{p}=0.028)$ and low $\operatorname{HDL}(\mathrm{OR}=2.2, \mathrm{p}=0.002)$ were associated with MSKD in DM. Also, poor glycemic control was more frequently observed in DM subjects with MSKD than in the DM subjects without MSKD.

\section{Numerical variables}

The median age was significantly higher among DM subjects with MSKD (65 years (58-70 years) vs 61 years (50.8-68 years), $\mathrm{p}=0.026)$. Similarly, the median duration of

Table I - Socio-demographic characteristics of subjects with diabetes and controls.

\begin{tabular}{|l|c|c|c|}
\hline Variables & $\begin{array}{c}\text { DM subjects } \\
\text { (N-268) } \mathbf{n}(\%)\end{array}$ & $\begin{array}{c}\text { Controls } \\
\text { (N-268) } \mathbf{n}(\%)\end{array}$ & p value \\
\hline Sex & $53(19.8)$ & $60(22.4)$ & 0.459 \\
\hline Male & $215(80.2)$ & $208(77.6)$ & \\
\hline Female & $133(49.6)$ & $110(41)$ & 0.281 \\
\hline Occupation & $71(26.5)$ & $95(35.4)$ & \\
\hline Traders & $29(10.8)$ & $26(9.7)$ & \\
\hline Office workers & $18(6.7)$ & $25(7.8)$ & \\
\hline Artisans & $5(1.8)$ & $6(2.2)$ & \\
\hline Manual workers & $12(4.5)$ & $10(3.7)$ & 0.001 \\
\hline Students & $77(28.7)$ & $79(29.5)$ & \\
\hline Others & $62(23.2)$ & $51(19.0)$ & \\
\hline Education & $28(10.4)$ & $108(40.3)$ & \\
\hline Primary education & $101(37.7)$ & $30(11.2)$ & \\
\hline Secondary education & \multicolumn{5}{|l|}{} \\
\hline Tertiary Education & &
\end{tabular}

Key: $\mathrm{DM}=$ diabetes, $\mathrm{n}=$ frequency of each variable, $\mathrm{N}=$ Total number of subjects in each group, $\%=$ proportion of each variable. 
Table II - Comparisons of MSKD between patients with diabetes and control group.

\begin{tabular}{|l|c|c|c|c|c|}
\hline Variables & $\begin{array}{c}\text { DM subjects } \\
(\mathbf{N}-268) \mathbf{n}(\%)\end{array}$ & $\begin{array}{c}\text { Controls } \\
(\mathbf{N}-268) \mathbf{n}(\%)\end{array}$ & $\begin{array}{c}\text { Odds } \\
\text { ratio }\end{array}$ & $\begin{array}{c}\text { Confidence } \\
\text { interval }\end{array}$ & P-value \\
\hline MSK conditions & $150(55.9)$ & $59(22)$ & 4.5 & $3-6.5$ & 0.001 \\
\hline Limited joint mobility & $37(13.8)$ & $15(5.6)$ & 2.7 & $1.4-5.1$ & 0.001 \\
\hline Osteoarthritis & $25(9.3)$ & $11(4.1)$ & 2.4 & $1.2-5.0$ & 0.016 \\
\hline Symptomatic lumbosacral spondylosis & $15(5.6)$ & $6(2.2)$ & 2.6 & $1.0-6.8$ & 0.045 \\
\hline Adhesive capsulitis & $12(4.5)$ & $4(1.5)$ & 3.1 & $1.0-9.7$ & 0.042 \\
\hline Trigger fingers & $12(12.5)$ & $5(1.9)$ & 2.5 & $0.9-7.1$ & 0.084 \\
\hline De Quervain's tenosynovitis & $12(12.5)$ & $6(2.2)$ & 2.0 & $0.7-5.5$ & 0.150 \\
\hline Rotator cuff tendinitis & $10(3.7)$ & $1(0.4)$ & 10.3 & $1.3-81.4$ & 0.006 \\
\hline Carpal tunnel syndrome & $7(2.6)$ & $5(1.9)$ & 1.4 & $0.4-4.5$ & 0.559 \\
\hline Bicipital tendinitis & $2(0.7)$ & $0(0)$ & 2.0 & $1.8-2.1$ & 0.499 \\
\hline Sub acromion bursitis & $3(1.1)$ & $2(0.7)$ & 1.5 & $0.3-9.1$ & 0.653 \\
\hline Gouty arthritis & $2(0.7)$ & $0(0)$ & 2.0 & $1.8-2.1$ & 0.499 \\
\hline Plantar fasciitis & $2(0.7)$ & $1(0.4)$ & 2 & $0.2-22.3$ & 0.563 \\
\hline Cervical spondylosis & $2(0.7)$ & $1(0.4)$ & 2 & $0.2-22.3$ & 0.563 \\
\hline Fibromyalgia & $1(0.4)$ & $1(0.4)$ & 1 & $0.1-16.1$ & 1.000 \\
\hline Lateral epicondylitis & $3(1.1)$ & $1(0.4)$ & 3 & $0.3-29.2$ & 0.315 \\
\hline Medial epicondylitis & $1(0.4)$ & $0(0)$ & - & - & 1.000 \\
\hline Dupuytren's contracture & $2(0.7)$ & $0(0)$ & 2.0 & $1.8-2.1$ & 0.499 \\
\hline More than one MSK condition & $2(0.7)$ & $0(0)$ & 2.0 & $1.8-2.1$ & 0.499 \\
\hline
\end{tabular}

Key: $\mathrm{DM}=$ diabetes, $\mathrm{MSK}=$ musculoskeletal, $\mathrm{n}=$ frequency of each variable, $\mathrm{N}=$ Total number of subjects in each group, $\%=$ proportion of each variable.

DM was significantly higher among DM cases with MSKD (12 years (10-15 years) vs 7.8 years (4-12 years). The DM subjects with MSKD had higher mean BMI, HbA1C, HDL-c and waist circumference. The comparisons of clinical, anthropometric, haematological and biochemical variables between the groups are shown in Tables III and IV.

\section{Predictors of MSKD among subjects with types 2 DM}

Further analysis of significant variables obtained from bivariate statistics with binary logistic regression showed that age $(\mathrm{OR}=2.1, \mathrm{CI}=1.5-2.6)$ and waist circumference $(\mathrm{OR}=3.0, \mathrm{CI}=2.6-3.4)$ are predictors of MSK conditions among types 2 DM subjects.

\section{DISCUSSION}

This present study is consistent with previous reports of higher prevalence of MSK conditions among subjects with T2DM as it demonstrates that they are 2.5 times more frequent in persons with DM (20-25). This difference is significant such that persons with DM have 4.5 times greater odds of developing MSKD. The reported prevalence of MSKD among diabetic patients varies widely depending on DM populations whether type 2 only, type 1 only or mixed, as well as the case definitions of MSK systems studied. Our finding is comparable to prevalence of $54 \%$ documented among Indian T2DM patients (26). However it is much higher than the prevalence of $42.58 \%$ by Ashishi et al. (1), $13.3 \%$ by Kidwal et al. (23) and $33.3 \%$ by Bhat et al. (21). The higher proportion of elderly patients in our series may explain in part the discrepancy between our prevalence result and others reported elsewhere. Three reports from Africa were from mixed DM populations (2729). Their results showed that MSK conditions were more common in type $2 \mathrm{DM}$ subjects than in type 1 subjects (Morocco 
(27)- type 2 DM 37.4 vs type 1 DM 17.2\%, Egypt (28)-type 2 DM 37\%, type 1DM $29 \%$, Ethiopia (29) - type 2 DM $21.3 \%$ vs type $1 \mathrm{DM} 10 \%$ ). It is thought that it may be explained by the propensity for type 2 subjects to develop MSKD as a result of obesity, reduced physical activity, older age, dyslipidaemia, and hyperuricemia.

The prevalence of specific musculoskeletal conditions varies across various studies. Osteoarthritis was the most common MSKD recorded among T2DM subjects in studies from Greece (30), Morocco (27) and India (1). Conversely, studies from Egypt (28), Pakistan (23), and USA (3) found adhesive capsulitis as the most frequent MSKD. The most frequent MSKD observed among DM subjects in the present study was limited joint mobility, followed closely by symptomatic osteoarthritis. This finding is in keeping with the report by Ray et al. (30), who documented limited joint mobility as the commonest MSKD among diabetic subjects. The differences may be attributed to scopes of MSKD studied as well as different case definitions used by various investigators.

Musculoskeletal conditions were more frequent in the female diabetics. This finding is in keeping with previous studies among Africans and non-Africans (2, 3, 29). This observation also mirrors the higher prevalence of MSKD among females than males in the general population (31). On the contrary, a study from India reported equal distribution of MSKD between male and female DM patients (1). While middle aged and elderly persons in the general population often have high frequency of MSK conditions due to age related degeneration of articular cartilage and peri-articular structures, this risk was found to increase in the presence of DM, $(22,32)$. In this study, the proportion of elderly DM subjects with MSK conditions was significantly higher than elderly DM subjects without

Table III - Comparisons of clinical, biochemical and haematological variables between diabetic patients with musculoskeletal conditions and diabetic patients without musculoskeletal conditions.

\begin{tabular}{|c|c|c|c|c|c|}
\hline Variables & $\begin{array}{c}\text { DM Cases } \\
\text { with MSS conditions } \\
n(\%) n-150\end{array}$ & $\begin{array}{c}\text { DM cases } \\
\text { without MSS conditions } \\
n(\%) n-118\end{array}$ & $\begin{array}{l}\text { Odds } \\
\text { ratio }\end{array}$ & $\begin{array}{l}\text { Confidence } \\
\text { interval }\end{array}$ & P-value \\
\hline \multicolumn{6}{|l|}{ Sex } \\
\hline $\begin{array}{l}\text { Male } \\
\text { Female } \\
\text { Elderly } \\
\text { No formal education }\end{array}$ & $\begin{array}{l}21(14.0) \\
129(86.0) \\
109(72.7) \\
68(45.3)\end{array}$ & $\begin{array}{l}32(27.2) \\
86(72.8) \\
67(56.8) \\
33(28)\end{array}$ & $\begin{array}{l}2.3 \\
2.0 \\
2.1\end{array}$ & $\begin{array}{l}1.2-4.2 \\
1.2-3.4 \\
1.3-3.6\end{array}$ & $\begin{array}{l}0.007 \\
0.007 \\
0.004\end{array}$ \\
\hline $\begin{array}{l}\text { Long term DM (>10 years) } \\
\text { Co-morbidity } \\
\text { Poor glycemic control } \\
\text { Use statins }\end{array}$ & $\begin{array}{l}132(88.0) \\
85(56.7) \\
127(84.7) \\
142(94.7)\end{array}$ & $\begin{array}{l}44(37.3) \\
53(44.9) \\
63(53.4) \\
76(64.4)\end{array}$ & $\begin{array}{l}12.3 \\
1.6 \\
4.8 \\
9.8\end{array}$ & $\begin{array}{l}6.6-22.9 \\
0.9-2.6 \\
2.7-8.5 \\
4.3-21.9\end{array}$ & $\begin{array}{l}0.001 \\
0.056 \\
0.001 \\
0.001\end{array}$ \\
\hline $\begin{array}{l}\text { Smoking history } \\
\text { Alcohol history } \\
\text { Metabolic syndrome } \\
\text { Hypertension } \\
\text { Hyperuricemia } \\
\text { Obesity }\end{array}$ & $\begin{array}{c}4(2.7 \%) \\
51(34) \\
107(71.3) \\
118(77.3) \\
78(52) \\
83(55.3)\end{array}$ & $\begin{array}{c}3(2.6) \\
42(35.6) \\
69(58.5) \\
77(65.2) \\
45(38.1) \\
47(39.8)\end{array}$ & $\begin{array}{l}0.96 \\
0.9 \\
1.8 \\
1.8 \\
1.8 \\
1.9\end{array}$ & $\begin{array}{l}0.21-4.4 \\
0.6-1.5 \\
1.1-2.9 \\
1.1-3.1 \\
1.1-2.9 \\
1.1-3.1\end{array}$ & $\begin{array}{l}0.950 \\
0.786 \\
0.028 \\
0.029 \\
0.024 \\
0.012\end{array}$ \\
\hline $\begin{array}{l}\text { Abdominal obesity } \\
\text { Reduced HDLc } \\
\text { Elevated TG } \\
\text { Elevated CRP } \\
\text { Elevated ESR }\end{array}$ & $\begin{array}{c}89(59.3) \\
107(71.3) \\
78(52) \\
67(44.7) \\
28(18.7) \\
\end{array}$ & $\begin{array}{l}69(58.5) \\
62(52.5) \\
54(45.8) \\
48(40.7) \\
20(16.9)\end{array}$ & $\begin{array}{c}1.0 \\
2.2 \\
1.3 \\
0.94 \\
1.1 \\
\end{array}$ & $\begin{array}{c}0.6-1.7 \\
1.4-3.7 \\
0.8-2.1 \\
0.56-1.57 \\
0.6-2.1 \\
\end{array}$ & $\begin{array}{l}0.887 \\
0.002 \\
0.311 \\
0.513 \\
0.716\end{array}$ \\
\hline $\begin{array}{l}\text { Anemia } \\
\text { Leukocytosis }\end{array}$ & $\begin{array}{c}7(4.7) \\
28(18.7)\end{array}$ & $\begin{array}{c}4(3.4) \\
21(17.8)\end{array}$ & $\begin{array}{l}1.4 \\
0.96\end{array}$ & $\begin{array}{c}0.4-4.9 \\
0.514-1.79\end{array}$ & $\begin{array}{l}0.601 \\
0.855\end{array}$ \\
\hline
\end{tabular}

$\mathrm{DM}=$ diabetes, $\mathrm{n}=$ frequency of each variable, $\mathrm{N}=$ Total number of cases in each group, $\%=$ proportion of each variable, HDLc = high density lipoprotein cholesterol, TG = triglycerides, $\mathrm{CRP}=\mathrm{C}$-reactive protein, $\mathrm{ESR}=$ erythrocytes sedimentation, $\mathrm{BMI}=$ body mass index. 
Table IV - Comparisons of clinical, anthropometric, haematological and biochemical variables between diabetic patients with and without MSKD.

\begin{tabular}{|l|c|c|c|c|}
\hline \multicolumn{1}{|c|}{ Variables } & $\begin{array}{c}\text { DM Cases with MSKD } \\
\text { Mean (SD) } \\
\mathrm{n}=150\end{array}$ & $\begin{array}{c}\text { DM cases without MSKD } \\
\text { Mean (SD) } \\
\mathrm{n}=118\end{array}$ & T-tests & P-value \\
\hline \#Age & $65(58-70)$ & $61(50.8-68)$ & MWU & 0.026 \\
Duration of DM & $12(10-15)$ & $7.8(4-12)$ & MWU & 0.001 \\
\hline BMI (kg/m²) & $29.9 \pm 5.3$ & $28.4 \pm 5.0$ & 2.311 & 0.022 \\
\hline WC (cm) & $90.7 \pm 11.8$ & $87.1 \pm 11.9$ & -2.490 & 0.013 \\
\hline HDLc (mg) & $60.0 \pm 20.0$ & $52.4 \pm 23$ & 2.911 & 0.004 \\
TG (mg) & $164.7(96.6-372.4)$ & $124.9(85-276.9)$ & MWU & 0.122 \\
\hline SUA (mg/dL) & $6.2(4.4-7.9)$ & $5.4(4.1-7.0)$ & MWU & 0.176 \\
\hline ESR (mm/hr) & $20(10-35)^{*}$ & $28(14.8-45)^{*}$ & MWU & 0.042 \\
\hline CRP (mg/dL) & $2.6(1.5-8.0)^{*}$ & $2.1(1.3-7.6)^{*}$ & MWU & 0.304 \\
\hline WBC(/103) & $6.7 \pm 2.5$ & $6.8 \pm 1.8$ & 0.397 & 0.691 \\
\hline PCV (\%) & $39(35-51)^{*}$ & $39(25-54)^{*}$ & MWU & 0.606 \\
FBG (mg/dL) & $125(58-485)^{*}$ & $128.5(58-429)^{*}$ & MWU & 0.745 \\
2HRPP (mg/dL) & $172(70-482)^{*}$ & $166.5(72-459)^{*}$ & MWU & 0.623 \\
HBAIC (\%) & $8.8 \pm 2.5$ & $7.7 \pm 2.5$ & -3.480 & 0001 \\
\hline
\end{tabular}

Key: Mann-Whitney U test (MWU) for skewed data, ${ }^{*}$ Median (interquartile range) for skewed data, BMI= body mass index, WC-waist circumference, HDLC= high density lipoprotein cholesterol, TG= triglycerides, CRP-c-reactive protein, ESR=erythrocytes sedimentation rates, SUA=serum uric acid, PCV=packed cell volume, $\mathrm{WBC}=$ white blood cells, $\mathrm{FBG}=$ fasting blood glucose, $2 \mathrm{HRPP}=2$ hour post prandial, HBA1C=glycated haemoglobin.

MSK conditions. This finding differs from a report in USA by Cheng et al. (25), who observed that young diabetic subjects (1844 years) had higher prevalence of MSKD compared with the elderly group (22.7\% vs $7.2 \%)$. The majority of our subjects with DM had no formal education and lack of formal education was more common in DM subjects with MSK conditions than in DM subjects without MSK conditions. Ashishi et al. (1) in India also documented that DM cases with MSK conditions had lower level of education than DM cases without MSK conditions. Nigerian diabetics with higher educational exposure may adhere more strictly to healthy lifestyle measures, regular drug therapy and regular clinic visits than those with low or no education, thus translating to fewer complications. This was corroborated by Ogbera et al who documented higher frequency of DM foot (at risk and non at risk foot) among DM subjects with lower education (33).

In comparison with DM subjects without MSKD, metabolic syndrome, obesity, hyperuricemia, reduced HDLc, use of statins, and hypertension were significantly more prevalent among DM subjects with MSKD and were found to have association with MSKD. The high prevalence of the aforementioned biochemical and clinical variables among DM patients with MSK conditions may reflect background prevalence of these factors among DM patients in the general populations. In a data from a sample of 7,714 people selected to represent the US population across all ages, metabolic syndrome was present in 59\% of individuals with OA and in $23 \%$ of the population without OA (34). Studies have also found that people with metabolic syndrome develop OA at an earlier age and have more generalised pathology, increased inflammation, and augmented intensive pain in the joints compared to those without the syndrome $(35,36)$.

Although, there have been inconsistent relationship between poor glycaemic control and MSK manifestations in DM in the literature, we found in bivariate analysis, an association between poor glycemic control and MSK conditions in DM. This result contrasts with reports from USA (3) and Scotland (37) that found no significant as- 
sociation between poor glycemic control and MSKD. However, it is in tandem with the reports among Arabs (38). Similarly, we found an association between DM duration and MSKD. Evidence has shown that prolonged hyperglycaemia causes glycosylation of proteins, microvascular abnormalities, and collagen accumulation in skin and periarticular structures. This results in changes in the connective tissue, and subsequent development of articular and periarticular diseases among diabetics (8).

The predictors of MSKD in DM vary across studies and the relationships of most of these predictors with MSKD have not been consistent. Among Ethiopians, sex, type of DM, and age were independent predictors of MSK conditions (29). Furthermore, previous studies $(1,3)$ have documented significant association of hypertension, comorbidity, waist circumference, and duration of T2DM with presence of MSK manifestations among DM subjects. Despite the results of bivariate analysis from this study showing strong association between some variables and MSK conditions, further test of these variables in multivariate analysis revealed that only age and waist conference were predictors of MSK conditions. The heterogeneity in methodology, sample size and study objectives adopted by different investigators may be the explanation for this disparity.

Musculoskeletal ultrasound and MRI would have increased diagnostic precision for soft tissue rheumatic conditions in this study but were not done in our subjects as diagnosis was mostly clinical.

\section{CONCLUSIONS}

Similar to previous reports, this study documented significantly higher prevalence of MSK conditions among diabetic subjects compared with the non-diabetic controls. It also identified certain factors associated with the presence of MSK conditions among persons with DM. Large prospective cohort studies will offer higher quality of evidence to answer if truly DM or poor glycemic control is a risk factor for MSKD in DM. We suggest that screening for MSK conditions should be an integral part of DM care plan.

Acknowledgments: the authors would like to thank the Nursing Staff of DM clinic of the Department of Medicine, Lagos State University Teaching Hospital.

Contributions: the authors contributed equally.

Conflict of interests: the authors declare no potential conflict of interests.

Funding: the study is self-funded by the authors

\section{REFERENCES}

1. Ashishi JM, Nair BJ, Pillai SS. RheumaticMusculoskeletal Manifestations in Type 2 Diabetes Mellitus Patients in South India. Int J Rheum Dis. 2011; 14: 55-60.

2. Akanji AO, Bella AF, Osotimehin BO. Cheiroarthropathy and Long-term Diabetic Complications in Nigerians. Ann Rheum Dis. 1990; 49: 28-30.

3. Cagliero E, Gary WA, Perlmutter S, et al. Musculoskeletal Disorders of the Hand and Shoulder in Patients with Diabetes Mellitus. Am J Med. 2002; 112: 487-90.

4. Sarkar RN, Banerjee S, Basu AK, et al. Rheumatological Manifestation of Diabetes mellitus. J Indian Rheum Assoc. 2003; 11: 25-9.

5. Shaw JE, Sicree SE, Zimmet PZ. Global estimates of the Prevalence of Diabetes for 2010 and 2030. Diabet Res Clin Pract. 2010; 87: 4-14.

6. Arkkila PE, Gautier JF. Musculoskeletal Disorders in Diabetes Mellitus: an Update. Best Pract Res Clin Rheumatol. 2003; 17: 945-70.

7. Crispin JC, Alcocer-Varela J. Rheumatologic manifestations of Diabetes Mellitus. American Journal of Medicine. 2003; 114: 753-7.

8. Kim RP, Edelman SV, Kim DD. Musculoskeletal Complications of Diabetes Mellitus. Clin Diabet. 2001; 1: 367-76.

9. Sergent JS. Arthritis accompanying Endocrine and Metabolic disorder. In: Firestein GS, Budd RC, Harris DE, McInnes BI, Ruddy S, Sergent JS, (eds). Kelley's Textbook of Rheumatology. $8^{\text {the }}$. Philadelphia, PA: W.B Saunders Publishers. 2008; 2187-9.

10. Leden I, Svensson B, Sturfelt G, et al. 'Rheumatic' Hand symptoms as a clue to Undiagnosed Diabetes Mellitus. Scand J Rheumatol. 1980; 9: 127-8.

11. Rosenbloom AL, Silverstein JH, Lezotte CD, et al. Limited Joint Mobility in Childhood Diabetes Mellitus Indicates Increased Risk for 
Microvascular Disease. N Engl J Med. 1981; 305: 191-4.

12. Pai L, Hung C, Li S, et al. Musculoskeletal pain in people with and without type 2 diabetes in Taiwan: a population-based, retrospective cohort study. BMC Musculoskel Disord. 2015; 16: 364.

13. Mobini M, Karim P, Muammadpour R, et al. Impact of Upper Limb Musculoskeletal Disorders on Quality of Life in Type 2 Diabetes Mellitus. J Clin Diagnost Res. 2018; 12: OC01-OC04.

14. Odusan O, Raimi HA, Oguntona SA, et al. Rheumatologic Disorders in Diabetes Mellitus: Case Reports and review of Literature. Nigerian Med Pract. 2011; 59: 1-2.

15. Kish L. Survey Sampling. New York: John Wiley and Sons Inc.; 1965.

16. ACR endorsed criteria: Available from: http:/ www.rheumatology.org/practice-quality/clinical-support/criteria/ACR-Endorsed-criteria

17. Harrington JM, Carter JT, Birrell L, et al. Surveillance case definitions for work-related upper limb pain syndromes. Occupat Environ Med. 1998; 55: 264-71.

18. Crawford F. Plantar heel pain (including plantar fasciitis). Clin Evid. 2001; 6: 918-26.

19. Bradley EM, Tennant A. Changing profile of joint disorders with age. Findings from a postal survey of the population of Calderdale; West Yorkshire, United Kingdom. Ann Rheum Dis. 1992; 51: 366-71.

20. Deshmukh DP, Akarte AG. Musculoskeletal manifestations in type 2 diabetes mellitus. Int J Res Med Sci. 2017; 5: 398-402.

21. Bhat TA, Dhar SA, Dar TA, et al. The Musculoskeletal Manifestations of Type 2 Diabetes Mellitus in a Kashmiri Population. Int J Health Sci Qassim Univ. 2016; 10: 1.

22. Mustafa KN, Khader YS, Bsoul AK, et al. Musculoskeletal disorders of the hand in type 2 diabetes mellitus: prevalence and its associated factors. Int J Rheum. Dis. 2016; 19: 730-5.

23. Kidwai SS, Wahid L, Siddiqi SA, et al. Upper limb musculoskeletal abnormalities in type 2 diabetic patients in low socioeconomic strata in Pakistan. BMC Res Notes. 2013, 6: 16.

24. Ramchurn N, Mashamba C, Leitch E, et al. Upper limb musculoskeletal abnormalities and poor metabolic control in diabetes. Eur $\mathrm{J}$ Intern Med. 2009; 20: 718-21.

25. Cheng YJ, Imperatore G, Caspersen CJ, et al. Prevalence of Diagnosed Arthritis and Arthritis-Attributable Activity Limitation Among Adults With and Without Diagnosed Diabe- tes: United States, 2008-2010. Diabetes Care. 2012; 35: 1686-91.

26. Sarkar P, Pain S, Sarkar RN, et al. Rheumatological manifestations in diabetes mellitus. J Indian Med Assoc. 2008; 106: 593-4.

27. Majjad A, Errahali A, Toufik H, et al. Musculoskeletal Disorders in Patients with Diabetes Mellitus: A Cross-Sectional Study. Int J Rheumatol. 2018; 2018: 3839872.

28. Youssef A, Shabana A, Senna M, et al. Study of musculoskeletal disorders in a cohort of Egyptian diabetic patients and its relation to glycemic control. Tanta Med J. 2016; 44: 4.

29. Fasika S, Abebe SM, Kebede AG. The prevalence of shoulder and hand complications and associated factors among diabetic patients at University of Gondar Teaching Referral Hospital in Northwest Ethiopia. J Diabet Res Clin Metab. 2013; 2: 8-12.

30. Ray S, Datta AK, Sinhamahapatra P, et al. Prevalence of rheumatic conditions in patients with diabetes mellitus in a tertiary care hospital. J Indian Med Assoc. 2011; 109: 74-8.

31. Palazzo C, Ravaud J, Papelard A, et al. The Burden of Musculoskeletal Conditions. PLoS One 2014; 9: 1-5.

32. Aghaei M, Basrafshan HR, Sedighi S, et al. Frequency of Rheumatological manifestations in diabetic patients in Gorgan, North of Iran. Int J Med Health Sci. 2013; 2: 1-7.

33. Ogbera AO, Adedokun A, Fasanmade OA, et al. The Foot at Risk in Nigerians with Diabetes Mellitus. The Nigerian Scenario. Int J Endocrinol Metab. 2005; 4: 165-73.

34. Singh G, Miller JD, Lee FH, et al. Prevalence of cardiovascular disease risk factors among US adults with self-reported osteoarthritis: data from the Third National Health and $\mathrm{Nu}-$ trition Examination Survey. Am J Manage Care. 2002; 8: S383-91.

35. Puenpatom RA, Victor TW. Increased prevalence of metabolic syndrome in individuals with osteoarthritis: an analysis of NHANES III data. Postgrad. Med. 2009; 121: 9-20.

36. Engstrom G, Gerhardsson de Verdier M, Rollof $\mathrm{J}$, et al. C-reactive protein, metabolic syndrome and incidence of severe hip and knee osteoarthritis. A population-based cohort study. Osteoarthritis Cartilage. 2009; 17: 168-73.

37. Thomas SJ, McDougall C, Brown ID, et al. Prevalence of symptoms and signs of shoulder problems in people with diabetes mellitus. J Shoulder Elbow Surg. 2007; 16: 748-51.

38. Attar MS. Musculoskeletal manifestations in diabetic patients at a tertiary centre. Libyan $\mathrm{J}$ Med. 2012; 7: 56-9. 